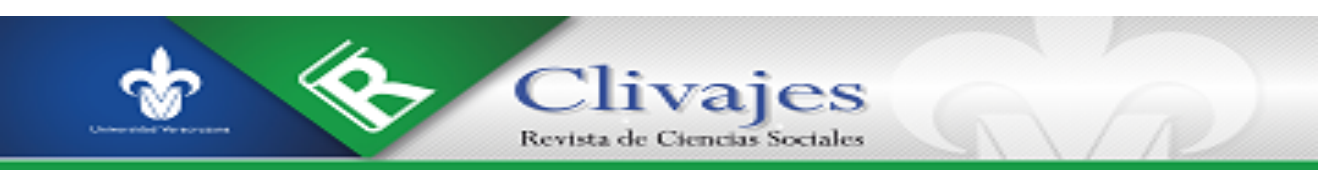

Víctor Manuel Andrade Guevara

EL 68 GLOBAL: REVOLUCIÓN Y CONTRACULTURA

Clivajes. Revista de Ciencias Sociales. Año V, nú mero 10, julio diciembre 2018, pp.1-20.

http://clivajes.uv.mx/index.php/Clivajes/editor/proofGalley/2549/4431

Instituto de Investigaciones Histórico-Sociales, Universidad Veracruzana

C livajes. Revista de Ciencias Sociales/ISSN: 2395-9495/IIH-S, UV/Xalapa, Veracruz, México.

Recibido: 03-09-2018

Aceptado: 10/09/2017

Dictaminado: 15/10/2018

Publicación: 06/12/2018

Clivaies. Revista de Ciencias Sociales (ISSN: 2395-9495). Año V. Núm. 10. iulio-diciembre. 2018 


\title{
El 68 GlOBAL: REVOLUCIÓN Y CONTRACULTURA
}

\author{
Víctor Manuel Andrade Guevara*
}

\begin{abstract}
Resumen
Este artículo emprende un balance del impacto del movimiento global de 1968 en la configuración del capitalismo contemporáneo, así como en el campo de las ciencias sociales. A diferencia de quienes sostienen que el movimiento cívico-estudiantil y la contracultura que le acompañó no tuvieron un impacto significativo en el ámbito político, aquí se afirma que la contracultura y los breves, pero intensos, momentos de experimentación de otras formas de participación política y de convivencia, junto con los valores contraculturales que le acompañaron, tuvieron una repercusión política, más allá de los modos de participación posibles en la democracia representativa.
\end{abstract}

Palabras clave: Movimiento estudiantil, Revolución, Contracultura

\section{EL MOVIMIENTO DEL 68: ACONTECIMIENTOS E INTERPRETACIONES}

¿Que ha quedado del movimiento global del 68 después de 50 años? Las representaciones o el imaginario cambian de significado según el punto de mira espacial y la perspectiva histórica que se utilice: el acontecimiento, la corta, larga o muy larga duración, si compartimos la idea de Fernand Braudel sobre los diferentes tipos de duración que operan en la historia. Todo indica que, a pesar de las enormes transformaciones sociales y culturales relacionadas con el cambio demográfico, el surgimiento y expansión del internet y las redes sociales, la globalización de la economía y la intensificación de la conectividad, la memoria del 68 aún guarda sentido como ejemplo de protesta y participación política. Los movimientos más recientes, cuyos principales protagonistas son los llamados millenials o la generación hashtag o hiperdigital (Feixa, Fernández-Planells y Figueras-Maz, 2016), se destacan por combinar la protesta en la plaza pública con la participación en redes sociales y el uso de dispositivos de comunicación, los cuales establecen conexiones globales a la vez que

\footnotetext{
* Víctor Manuel Andrade Guevara es Licenciado en Sociología (Universidad Veracruzana), maestro en Ciencias con Especialidad en Administración Pública (Instituto Politécnico Nacional) y doctor en Historia y Estudios Regionales por la Universidad Veracruzana. Docente de la Facultad de Sociología de la Universidad Veracruzana, de la Maestría en Ciencias Sociales y del Doctorado en Historia y Estudios Regionales, es también miembro del Sistema Nacional de Investigadores, Nivel I, así como del Cuerpo Académico "Estudios sociopolíticos" con las líneas de investigación Cultura de la legalidad; Poder legislativo y espacio público; e Historia de la izquierda en Veracruz.
} 
favorecen un proceso de deslocalización o glocalización. Es el caso de movimientos tales como el 15M, Occupy Wall Street, la Primavera Árabe o el movimiento Yosoy132. Frente al lugar común que identifica a la generación millenial como una masa de jóvenes atomizados, consumistas, hedonistas y recluidos en lo privado, los jóvenes han incrementado el repertorio de acciones a través de los cuales expresan sus visiones acerca de lo público, sin descartar la participación política vinculada a partidos o candidatos como sucedió en la primera campaña de Obama y recientemente en el triunfo de López Obrador en México.

Según una encuesta levantada en México, en 2014, por el Gabinete de Comunicación Estratégica, para el 46\% de la población el 68 aún tiene sentido, mientras que para el 45\% dejó de tener influencia. Cabe mencionar, sin embargo, que cuando se preguntó a los encuestados si estaban de acuerdo con la expresión "protestar no sirve para nada", el 36\% dijo estar totalmente en desacuerdo, el 16\% algo en desacuerdo, el 16\% totalmente de acuerdo y el 25\%, parcialmente de acuerdo. En términos gruesos, el 52\% opina que vale la pena protestar y el $41 \%$ que no (NTR, 2014).

¿Eran los jóvenes rebeldes del Mayo Francés una masa en busca de un amo, como señaló en su momento Jacques Lacan, o representaban, por lo contrario, la continuidad de la toma de la Bastilla, la Revolución de 1848 y la Comuna de 1871, imbuidos del espíritu que animó la construcción de la Segunda República?

¿Cuál era el potencial de transformación de los jóvenes movilizados en Praga, en Berkeley, California; en Alemania, México, Tokio, Río de Janeiro o Buenos Aires? La primera impresión que se tiene del movimiento del 68, a diferencia de los movimientos contemporáneos, es que los jóvenes de aquella época luchaban por el futuro; no obstante, para observadores agudos como Octavio Paz:

El sentido profundo de la protesta juvenil, sin ignorar sus razones ni sus objetivos inmediatos y circunstanciales, consiste en haber opuesto, al fantasma implacable del futuro, la realidad espontánea del ahora. La irrupción del ahora significa la aparición, en el centro de la vida contemporánea, de la palabra prohibida, la palabra maldita: placer. Una palabra no menos explosiva y no menos hermosa que la palabra justicia (Paz, 1970: 26-27; énfasis en el original).

Desde la serenidad que le otorgaba su posición de espectador conservador, Raymond Aron (1983) señalaba que los acontecimientos del Mayo Francés habían significado una revolución embrionaria, producto de la excesiva centralización del gobierno y de la extrema radicalización de los intelectuales, estimulados por el opio de 
la ideología. Su reflexión sociológica le llevaba a afirmar en sus memorias, que la explicación de las movilizaciones del 68 inevitablemente remitía a situaciones nacionales, aunque hubiera elementos culturales comunes con las movilizaciones ocurridas en otros países, relacionados, sobre todo, con el desafío a la autoridad y a los adultos. Este pensador también enfatizaba el hecho de que la revuelta francesa fue la única en la que se involucraron los obreros, mientras que no lo hicieron para apoyar las protestas contra la guerra de Vietnam en los Estados Unidos o en Alemania.

El relato sociológico de mayo de 1968 me parece a la vez más fácil y más difícil que el de los acontecimientos del último siglo. Más fácil porque los movimientos estudiantiles y obreros fueron distintos y porque no hubo revolución; más difícil porque los estudiantes, los agitadores, no remiten a ninguna clase, aunque de palabra se reclamen de la clase obrera que no por ello los reconoce. En cuanto a los obreros, su conducta depende, por una parte, de la táctica del partido comunista, por la otra, de sus propios sentimientos (Aron, 1983).

La obra de Alain Touraine (1969), publicada inmediatamente después de los acontecimientos, consideraba al movimiento de mayo como la expresión de una contradicción entre la fascinación por la técnica y el productivismo, propios de la sociedad postindustrial, y el rechazo a estas lógicas por los actores emergentes o por quienes representaban tendencias más tradicionales. Se trataba de las contradicciones reprimidas entre la lógica de la modernización tecnológica y el tradicionalismo del poder estatal francés, demasiado centralizado. Ello traía consigo la emergencia de un nuevo sujeto de clase que protestaba por la ausencia de una reforma académica en las universidades, retrasadas ante las tendencias que imponían la modernización y el advenimiento de una sociedad postindustrial cuya base de reproducción era precisamente el conocimiento.

Para Cornelius Castoriadis (2009), el movimiento francés obedecía a una lucha antiautoritaria que tenía como sujeto, no a la clase obrera tradicional ni a los estudiantes, sino, en general, a los asalariados. Mayo del 68 fue, en buena medida, una revolución prematura que no pudo conducir a la autonomía de una sociedad autoinstituyente, liberada de las restricciones que imponía la lógica del capitalismo.

Para quienes, como Wallerstein (1990), se valen de la Teoría de los Sistemas Mundiales, el 68 fue una revolución en contra del sistema mundial y la hegemonía que en él ejercían los Estados Unidos de América, con la aquiescencia de la Unión Soviética. Recordemos que para Wallerstein, la construcción del imperio soviético, lejos de fortalecer la lucha anticapitalista de las clases subalternas de occidente y el resto del mundo, había contribuido a su contención. En ese marco del movimiento global de 
1968, emergieron nuevos sujetos que se oponían a los que en ese momento protagonizaban la lucha por el cambio social; esto es, el movimiento comunista, la socialdemocracia y los movimientos nacionalistas, la llamada vieja izquierda. El cuestionamiento a los dos primeros se dio, sobre todo, en Francia y, en menor medida, en Alemania. De esa guisa participaría el movimiento de la Primavera de Praga que apostaba por la construcción de un "socialismo con rostro humano", mientras que el movimiento del 68 mexicano cuestionó a las élites que promovieron el nacionalismo a partir de la Revolución mexicana. Los estudiantes, el ecologismo, los nuevos movimientos contra el racismo y la lucha feminista, así como la llamada nueva izquierda, serían parte de esos nuevos sujetos. Wallerstein sostenía también que la contracultura, "aunque formó parte de la euforia revolucionaria, políticamente no fue central" (Wallerstein, 1990: 24).

Con la excepción de Aron (1983), ninguno de los autores antes señalados menciona el elemento cultural promovido por la obra de Herbert Marcuse (1978), que apuntaba a la construcción de nuevas subjetividades y a una renovación de las formas de vida en ámbitos como la sexualidad, las relaciones con la naturaleza y las formas de convivencia familiar. La mayoría de ellos comparte el principio de que las contradicciones o conflictos se dieron a partir de los intereses objetivos, ya sea en el ámbito de la economía o de la política. Aún el situacionismo, que había hecho un diagnóstico de la coyuntura, bastante iluminador, y que anticipó algunos de los acontecimientos desarrollados en Nanterre y París, redujo la importancia de los estudiantes en el movimiento de mayo, señalando que sólo dieron el impulso inicial, pero que, después del 11 de mayo, cuando inició la huelga general, el peso principal de la lucha recayó en el movimiento obrero.

En términos similares se expresaba Jean Meyer (2008), señalando que, debido a la transitoriedad de su rol, así como a las diferencias de clase que caracterizaban a los propios estudiantes, la influencia política de éstos en América Latina había sido menor históricamente. Los estudiantes pobres estaban destinados a regresar a sus grupos de origen y los estudiantes de clase media y alta se convertirían, con el paso del tiempo, en parte de las élites dirigentes.

Si se parte de la escala global, el 68 inició efectivamente con la Primavera de Praga, a partir del cambio de Antonín Novotny por Alexander Dubcek. El movimiento de la Primavera de Praga se prolongó con la intervención de los obreros y la formación de consejos de empresa que pretendían conducir de manera autogestiva la producción y administración de los bienes. 
En los Estados Unidos de América, las manifestaciones estudiantiles que protestaban contra la guerra de Vietnam y promovían un cambio en las formas de vida, oponiéndose al consumismo, a los efectos negativos de la tecnología y el recurso de la guerra para dominar al mundo, se combinaron con la lucha por los derechos humanos y contra la discriminación racial que, para entonces, habían emprendido las comunidades negras, encabezadas por Martin Luther King y Malcom X. El boom de la literatura beat producida por Allen Ginsberg, Jack Kerouac y William Borroughs; el rock and roll de Chuck Berry, Elvis Presley y Little Richard; la música de Joan Báez y Bob Dylan, y las afirmaciones de Herbert Marcuse acerca de los estudiantes como nuevos sujetos de la revolución, configuraron una transformación cultural que amplió el universo de significaciones, dando un nuevo sentido a la vida, especialmente a la condición de ser joven. En 1958 se había publicado Eros y civilización, y en 1964 El hombre unidimensional, ambos de Herbert Marcuse.

La primera obra articulaba creativamente las concepciones marxista y freudiana para actualizar la crítica al capitalismo, señalando la represión generada por el proceso de civilización y la sobre-represión a la que se veían sometidos los trabajadores, develando la falsa liberación ofrecida por la publicidad, que fomentaba el consumo recurriendo a la estimulación de los instintos básicos, principalmente el sexo, acuñando el concepto de “desublimación represiva". El hombre unidimensional era una crítica actualizada de la alienación hegeliano-marxista a la que se veían sometidos los seres humanos en el capitalismo, al ser reducidos a consumidores de productos que se fabrican para satisfacer necesidades falsas. Esta unidimensionalidad incluía a la clase obrera que, en occidente, habría sido integrada a la lógica del consumo. Las ideas de Marcuse apuntaban a la construcción de una nueva utopía que luchaba contra el carácter afirmativo de la cultura y apostaba por la construcción de nuevas formas de vida orientadas a la liberación de las capacidades humanas y las potencialidades plenas del cuerpo.

Al parecer, estaban más presentes en Alemania la simpatía con los movimientos de liberación nacional del tercer mundo, y especialmente la oposición a la guerra de Vietnam. El peso de la herencia nazi ensombrecía la vida pública alemana y, en cierta medida, el movimiento estudiantil que se basaba, sobre todo, en la presencia de la Federación Socialista Alemana de Estudiantes (SDS por sus siglas en alemán) sirvió para sacudirse ese pasado nazi, empezando por la reforma académica e institucional de las universidades. Al igual que en el resto de occidente, la universidad alemana enfrentaba el dilema entre mantener el viejo ideal expresado por Humboldt, orientado a la 
construcción de un espacio para una formación humanística que influyera en la constitución de un sujeto autónomo y con vocación universalista, o adaptarse a las tendencias que venía imponiendo el desarrollo científico y tecnológico y la necesidad capitalista de contar con personal técnicamente calificado, capaz de innovar y contribuir a la elevación de la productividad.

El movimiento estudiantil alemán estaba dividido en varias tendencias, la mayoría ligadas a la SDS, quienes consideraban que el sujeto del cambio social seguía siendo básicamente la clase obrera. La fracción mayoritaria, en cambio, se apoyaba en el diagnóstico elaborado por los autores de la escuela de Frankfurt, principalmente Adorno y Marcuse, en el sentido de que el sujeto de cambio no podía ser solamente la clase obrera, debido a que el entorno autoritario exacerbado por la cultura y las instituciones nazis habían dado lugar a la forja de personalidades autoritarias, aún entre los obreros y al interior de sus familias, por lo que el nuevo sujeto debería constituirse a partir de una ruptura de carácter intelectual, en primer lugar, en la que jugaban un papel destacado los estudiantes (Kellner, 2018).

El asesinato de Benno Ohnesorg, durante las jornadas de protesta contra la visita del Sha de Irán, en 1967, encendió los ánimos, dando lugar al surgimiento del movimiento Dos de Junio. La realización de un congreso en contra de la guerra de Vietnam, en febrero de 1968, confluyó con el movimiento estudiantil por la reforma universitaria. Como se recordará, a pesar de que los intelectuales de la Escuela de Frankfurt se venían pronunciando por la democratización de la enseñanza superior y, sobre todo, en la versión de Habermas (2008), por el control democrático y racional de la generación del conocimiento, en su momento se manifestaron contra lo que consideraban un exceso del movimiento estudiantil, cuyo asambleísmo, pensaban, subvertía totalmente las reglas del debate académico y corría el peligro de desembocar en un fascismo de izquierda.

En otros países de Europa, como España y Finlandia, y otras regiones del planeta, principalmente en México, Brasil, Argentina o Japón, hubo también revueltas que significaron un vuelco en la vida política de esos países, aunque tampoco hayan puesto en peligro el mantenimiento del poder por parte de las élites hegemónicas.

El movimiento de 1968 en México, precedido de una serie de luchas que cuestionaban la legitimidad del régimen posrevolucionario y habían sido reprimidas por el gobierno, tales como la huelga ferrocarrilera, el movimiento magisterial de 1958 y el movimiento médico de 1964, amplió sus demandas iniciales, ligadas específicamente con el conflicto estudiantil, llegando a plantear cuestiones como la desaparición de los 
cuerpos de granaderos, la destitución de los cuerpos policiacos y la indemnización a los familiares de los estudiantes agredidos durante la represión, hasta el reclamo de la libertad a los presos políticos y la derogación del artículo 145 y 145 bis del código penal federal que establecía el delito de disolución social.

De esa manera, el conflicto, inicialmente vinculado a las demandas estudiantiles, se amplió hasta el cuestionamiento de las prácticas antidemocráticas del régimen (Álvarez Garín, 1998; Guevara Niebla, 2008). Sin lugar a dudas, gran parte del movimiento estaba dirigido por militantes de izquierda, lo mismo comunistas, maoístas y trotskistas, que del nacionalismo revolucionario, aunque los integrantes del $\mathrm{CNH}$ representaban una diversidad muy amplia, que excedía a las agrupaciones de izquierda (Zermeño, 1978; Aguayo 2018). Si bien las demandas al gobierno tenían que ver con asuntos de orden político nacional, la simbología que rodeaba al movimiento expresaba elementos característicos de los demás movimientos en el orbe, como el cuestionamiento por la guerra de Vietnam y la simpatía con los movimientos de liberación nacional; en suma, en contra de la guerra total a la que Estados Unidos condenaba a la humanidad, y que Jean Paul Sartre denunciaba, apoyado desde México por intelectuales como José Revueltas (1978).

En Argentina, gobernada por una dictadura que había depuesto al presidente Arturo Umberto Illia, el movimiento del 68 se generó, sobre todo, en el seno de la clase obrera y sectores populares, incluyendo intelectuales y artistas inconformes con el monopolio cultural que, hasta entonces, había ejercido el corporativo Di Tella. Algunos sectores sindicalistas del peronismo mantuvieron las protestas contra las medidas tomadas por la dictadura y crearon una central sindical alternativa a la que, tradicionalmente, había ejercido la hegemonía. Serían las dos centrales obreras, en conjunción con el movimiento estudiantil que había mantenido una ola de protestas contra la censura a la prensa y por el respeto a la libertad de cátedra, quienes, en mayo de 1969, encabezarían la insurrección popular conocida como "cordobazo", convocando a una huelga general que fue reprimida también por el ejército, teniendo como resultado decenas de muertos y heridos (Tarcus, 2008).

Una situación similar ocurría en Brasil: las protestas estudiantiles en Río de Janeiro, durante las jornadas de junio, fueron aplastadas por la dictadura de Artur Costa da Silva, dando lugar a la manifestación multitudinaria del 26 de junio de 1968, en la que participaron, en promedio, cien mil personas.

Si lo vemos en perspectiva, ninguno de los movimientos señalados, salvo el de la Primavera de Praga, impactó en la modificación de las estructuras políticas en el corto 
plazo, aunque en el caso de Checoslovaquia, los cambios fueron aplastados por la intervención militar soviética. En varios de ellos, se registraron reformas universitarias de mayor o menor alcance, o bien, dieron lugar a un proceso de apertura política paulatina, como en el caso de México. En Francia, después de las grandes huelgas y la intervención decisiva de la clase obrera, las elecciones legislativas de junio de 1968, en las que la derecha obtuvo una mayoría absoluta, demuestran los alcances y las limitaciones del Mayo Francés, si bien el movimiento en su conjunto no se planteaba modificar las estructuras políticas a través del voto, en la medida en que la configuración del poder estatal y las fuerzas en él representadas les despertaban rechazo.

En el caso de Alemania, el gobierno de coalición entre la Democracia Cristiana y el Partido Socialdemócrata Alemán generaba también un rechazo entre los estudiantes, de tal suerte que se plantearon más bien la constitución de una oposición antiparlamentaria.

En los Estados Unidos, el bipartidismo predominante no daba posibilidad alguna de canalizar políticamente las demandas estudiantiles y juveniles, aunque en el espacio local la agenda de la llamada nueva izquierda llegó a tener expresiones aisladas, como algunas comunidades intencionales hippies, que se propusieron crear comunas en las que imperaban valores ligados a la contracultura y el anticapitalismo. Esta influencia limitada en la modificación de las estructuras políticas no debe llevarnos a aceptar sin más el veredicto de Hobsbawm, según el cual el movimiento del 68 no implicó una revolución o no tuvo una repercusión en el largo plazo:

El motivo por el que 1968 (y su prolongación en 1969 y 1970) no fue la revolución, y nunca pareció que pudiera serlo, fue que los estudiantes, por numerosos y movilizables que fueran, no podían hacerla solos. Su eficacia política descansaba sobre su capacidad de actuación como señales y detonadores de grupos mucho mayores pero más difíciles de inflamar. Desde los años sesenta los estudiantes han conseguido a veces actuar así: precipitaron una enorme ola de huelgas de obreros en Francia y en Italia en 1968, pero, después de 20 años de mejoras sin paralelo para los asalariados en economías de pleno empleo, la revolución era en lo último que pensaban las masas proletarias (Hobsbawm, 1998: 301).

El estudio realizado por Tarrow (1994), sobre los movimientos del 68 y el seguimiento a quienes jugaron un papel de liderazgo, le llevó a la conclusión de que buena parte de éstos decidieron seguir participando, principalmente en los partidos o movimientos verdes en Europa, mientras que otros quedaron atrapados en una 
situación de desadaptación crónica, cada vez más aislados en torno a una subcultura del movimiento (p. 296).

\section{LA CONTRACULTURA COMO FORMA DE REVOLUCIÓN POLÍTICA}

A contrapelo de lo que opinan Wallerstein (1990), Hobsbawm (1998) y los teóricos de la Movilización de Recursos, los movimientos ocurridos en el 68 parecen responder mejor a las categorizaciones realizadas por Alain Touraine (1995), en el sentido de que los movimientos sociales se caracterizan, ante todo, por su orientación cultural y su intervención en la modificación de los valores que rigen a una sociedad, antes que a una movilización de recursos por parte de actores que observan modificaciones en la estructura de oportunidades políticas. No es casual que en el mismo año de las revueltas estudiantiles se haya publicado el libro de Theodore Roszak (1970): El nacimiento de una contracultura, introduciendo, por primera vez, el concepto en el campo de las ciencias sociales. Su planteamiento coincide en lo esencial con los autores mencionados, en el sentido de que la contracultura es básicamente una reacción a la sociedad tecnocrática.

Para Roszak, la contracultura era un espacio cuyos contornos no estaban perfectamente definidos; incluía el bohemismo ambulante de beats y hippies, el audaz activismo de la política estudiantil, la sociología neoizquierdista de Charles Wright Mills, el marxismo freudiano de Herbert Marcuse, la terapéutica anarquista de Paul Goodman, el misticismo apocalíptico de Norman Brown - que también intentaba hacer una síntesis entre Freud y Marx-, la psicoterapia de origen zen de Alan Watss y el narcisismo de Timothy Leary, excluyendo en cambio a los marxistas de la vieja escuela o a los jóvenes militantes negros que, desde su punto de vista, adolecían de una concepción étnica reduccionista (Roszak, 1970: 11).

En México también se desarrolló una expresión de la contracultura, descrita y analizada con amplitud por autores como José Agustín (2001) o Enrique Marroquín (1975). Para José Agustín, la contracultura mexicana debería entenderse como: "Toda una serie de movimientos y expresiones culturales, usualmente juveniles, que rebasan, rechazan, se marginan, se enfrentan o trascienden la cultura institucional” (p. 129).

A pesar de utilizar, en cierto sentido, un lenguaje marxista y hegeliano, para José Agustín, la contracultura no tiene que ver con la militancia política; se orienta más bien a una forma de protesta basada en la formación individual. El repertorio de manifestaciones culturales que formarían parte de este movimiento va desde los 
pachucos y los cholos, los jipitecas, la música rock en sus distintas vertientes, hasta llegar a los darketos, góticos y demás movimientos underground. El escenario contracultural mexicano fue encontrando, poco a poco, su propia expresión en este proceso, incluyendo la llamada "literatura de la onda", de la que formarían parte las propias obras de José Agustín y Parménides García Saldaña, entre otros autores.

Por momentos, la domesticación de la onda sicodélica en México, a través de la subsunción por los medios de comunicación hegemónicos y el espíritu rebelde de la contracultura, convergieron en programas y propuestas culturales, como los efectuados por Alejandro Jodorowsky y Alfonso Arau, tal cual lo documenta Erick Zolov (2009). Hoy sabemos que el propio festival de Avándaro de 1971, al mismo tiempo que se convirtió en uno de los principales símbolos de la contracultura, tuvo como promotores a Televisa y los intereses comerciales de algunas firmas; no obstante, como dice Zolov:

¿Qué era la contracultura mexicana después del 68, en Avándaro? ¿Quiénes eran los que se huían a formar comunas en Oaxaca y Morelos, a buscar nuevas prácticas espirituales y religiosas, a experimentar con nuevas formas de arte, de teatro, a buscar nuevas relaciones con los indígenas?... Ojalá podamos rescatar esa historia, la otra cara del movimiento del '68, la cara temida por las mayorías, la cara contracultural. Porque fue esa cara, la que tuvo un impacto tan importante como el movimiento estudiantil: la onda logró transformar los valores culturales tradicionales mexicanos, y así cimentar las bases para una transición democrática que tardaría en llegar (2009: 107).

Sin duda, en su momento los valores enarbolados por los movimientos del 68 significaron una revolución cultural. La crítica al orden hegemónico mundial detentado por los Estados Unidos de América, expresada en las protestas contra la guerra de Vietnam, cuestionaba el orden mundial establecido a partir de la guerra fría y era una rebelión contra los dos bloques dominantes: el occidental y el comunista, incluyendo el apoyo a las luchas de liberación y los procesos de descolonización que tenían lugar entonces. La intervención de intelectuales como Jean Paul Sartre en apoyo a las luchas de liberación, sintomáticamente, en el prólogo a Los condenados de la tierra (1961) de Franz Fanon, favorecieron el apoyo político de la sociedad civil occidental.

Es cierto que parte de esas expresiones de rebeldía fueron utilizadas y resignificadas posteriormente por la propia industria cultural, en el sentido usado por la Escuela de Frankfurt para expandir el consumo y despojar a los símbolos más representativos de la rebelión cultural de su potencial subversivo, volviéndolos un objeto de consumo más (Heath y Potter, 2005). En cierta medida, La sociedad del 
espectáculo, de Guy Debord (1995), podría ser utilizada para interpretar los acontecimientos del 68 como un escenario que performativamente creaba las condiciones para la espectacularización de la protesta colectiva y de las manifestaciones individuales de rebeldía. La sociedad del espectáculo no se refería únicamente al papel creciente de los medios de comunicación, sino a la absorción total de la sociedad en el sistema económico, a la reducción total de los trabajadores y los seres humanos al mero papel de espectadores de la reproducción ampliada del capital.

Desde un ironismo liberal y posmoderno, Heath y Potter (2005) se solazaron señalando cómo los principales centros de creación contraculturales se convirtieron en productores de mercancías y pasaron a formar parte de la industria cultural capitalista, en un principio, objeto de su crítica. Estos autores eligieron como uno de sus ejemplos el suicidio de Kurt Cobain, motivado supuestamente por la contradicción existencial que envolvía al vocalista de Nirvana por su crítica a la subsunción de la cultura hippie por la industria cultural, mientras su grupo vendía más discos que Michael Jackson.

Quizá el impacto más profundo de los movimientos del 68, antes que su fijación en la memoria colectiva, fue el haberse construido como un arquetipo de movilización colectiva que sirvió para intensificar la imaginación en el seno de las ciencias sociales, constituyéndose en un acicate capaz de agudizar el debate y obligar a la comunidad académica a replantearse radicalmente la manera de pensar a las sociedades y estudiar el cambio social.

Al momento que surge el movimiento del Mayo Francés, el estructuralismo ocupaba el centro de la discusión académica, habiendo desplazado el predominio que por muchos años había ejercido el marxismo existencialista de Jean Paul Sartre. El debate sostenido entre Jean Paul Sartre y Claude Levi-Strauss, a raíz de la publicación de El pensamiento salvaje (1964), parecía haber zanjado las cosas a favor del segundo. Entre 1967 y 1968, de acuerdo con Francois Dosse, salieron también los volúmenes segundo y tercero de las Mitológicas de Levi Strauss, mientras que la aparición de Las Palabras y las cosas de Michel Foucault (1966), dio lugar a un debate en Les Temps Modernes.

En la opinión pública francesa se identificaba a Levi Strauss, Roland Barthes, Jacques Lacan y Michel Foucault como los cuatro mosqueteros del estructuralismo. La irrupción del movimiento de mayo, que llegó a involucrar a poco más de 10 millones de huelguistas, sirvió, sin embargo, para que las ideas de Jean Paul Sartre volvieran por sus fueros. En ese momento, la idea del grupo que se elevaba a la historia rompiendo con la serialidad, mediante la praxis, parecía mucho más convincente que la de una 
combinatoria de estructuras que modelan la formación de los sujetos. Si bien es cierta la anécdota acerca de Lacan cuando se refería a una movilización como una masa en busca de un amo, es necesario decir que este mosquetero estructuralista, junto con otros intelectuales, como Henri Lefebvre, Jean Paul Sartre y Maurice Blanchot, firmaron un manifiesto a favor del movimiento el 10 de mayo, justo un día antes de La Noche de las Barricadas (Dosse, 1992: 132). Ese manifiesto señalaba, entre otras cosas:

Estamos dispuestos a afirmar que, frente al sistema establecido, el movimiento estudiantil es de una importancia capital y quizás decisiva, ya que, sin hacer promesas y, por el contrario, descartando toda afirmación prematura, opone y mantiene una potencia de rechazo capaz, creemos nosotros, de abrir un porvenir (Marcuse, 1978: 52).

La expansión de la matrícula universitaria, posibilitada por el crecimiento económico originado durante los 30 dorados años del capitalismo, incrementó el número de profesores $\mathrm{y}$, sobre todo, el número de estudiantes en la mayoría de países occidentales, así como en Japón y los países del llamado Tercer Mundo (Hobsbawm, 1998: 299), en un contexto marcado por la guerra fría, las luchas por la descolonización y el cambio tecnológico. Las ideas de pensadores como Marcuse (1978), que coincidieron con la difusión de la cultura beat y la protesta generacional de los hijos de los obreros en países como Inglaterra, quienes veían con hartazgo la inevitabilidad de su incorporación a una vida limitada, similar a la de sus padres, configuraron una mezcla potente para el llamado al cambio social, a menudo, mas allá de las estructuras políticas. Los códigos del cambio social y cultural que promovían estos colectivos no necesariamente se podían traducir a los que regían la política en esos momentos. La gran mayoría de los jóvenes no se identificaba necesariamente con el conservadurismo norteamericano o los regímenes comunistas, ni siquiera con el reformismo socialdemócrata en el caso de Europa.

Es cierto que algunas agrupaciones, apoyadas en las elaboraciones intelectuales de pensadores como Marcuse, Sartre, Guy Debord o Castoriadis, y el grupo "Socialismo o Barbarie", se expandieron y pusieron en marcha proyectos autogestionarios y comunidades que experimentaban con otras formas de organización política y otras normas de vida, aunque no lograron extender su influencia a mediano plazo. Por ello, debemos tomar con reservas el juicio de Eric Hobsbawm (1998), en el sentido de que el 68 no significó una revolución. Si bien no lo fue en el sentido tradicional del término, o como se había entendido desde el marxismo, como una modificación radical de las estructuras políticas y sociales, lo fue, y en un sentido muy 
profundo, en el aspecto cultural. Si bien quedaron intactas las estructuras de dominación capitalista y la sociedad del consumo no sólo no se contuvo, sino que se expandió, hubo una revolución radical en las formas de vida y en la construcción de la subjetividad.

De esta manera, el problema de la subjetividad, que en la teoría marxista clásica apelaba solamente a la conciencia de clase, se vio modificada y complementada por la recuperación de la idea de ciudadanía y la identidad. En adelante, para cualquier diagnóstico del capitalismo, sería necesario un análisis de las formas en que las estructuras de la vida social y política se expresaban en la vida cotidiana y las necesidades de los individuos. A principios de los años 70, la crisis de legitimación del capitalismo tardío de la que hablaba Habermas (1999) se refería no sólo a una crisis del sistema económico y del sistema político, sino también a una crisis "de motivación”.

La atracción por la cultura oriental que caracterizaba a los Beatles en su última etapa y al pacifismo de John Lennon, que se combinó con un mensaje más directamente político en piezas como Working class heroe, o en su colaboración con Timothy Leary en el movimiento Come Together son expresión de esta convergencia entre la contracultura y la protesta política que apuntaba al resurgimiento de la utopía. Una idea sugerente planteaba Stuart Hall (1970) al señalar la existencia de dos polos en el espacio de la contracultura: el polo expresivo y el polo activista; el primero, más orientado a mostrar un mensaje de cambio a través de la música, el vestuario y la estilización del cuerpo, mientras que el segundo asumía una dimensión más estratégica, orientada a la construcción de formas políticas alternativas a las del Estado y el uso de la protesta.

La crisis del marxismo, agudizada al final de los años setenta, así como el influjo del posmodernismo que pretendía dar cuenta de los grandes paradigmas en ciencias sociales, permitieron reflexionar sobre el 68 desde una perspectiva más serena conforme fueron pasando los años y pudieron ser enmarcados los hechos en un horizonte histórico más amplio. El breve auge que tuvieron los llamados nuevos filósofos (André Glucksmann, Bernard Henry Leví o Alain Finkielkraut) dio lugar a lecturas conservadoras e incluso liberales. Ellos vieron al 68, particularmente en la experiencia del Mayo Francés, como un movimiento que reflejaba la crisis de la idea de revolución en su sentido clásico, cuya última oleada provenía de la Revolución de octubre de 1917, es decir, de la idea de que la revolución implicaba la toma del poder del Estado y estaría dirigida por una vanguardia o partido político.

Para un filósofo conservador como Luc Ferry (1965), el movimiento del 68 no estaba en contra de la sociedad de consumo, sino a favor de ésta, en la medida en que 
promovía un hedonismo que recomendaba "disfrutar sin obstáculos" y destruir los valores tradicionales para que el capitalismo globalizado floreciera (Ferry, 1985: 19).

Jean Francois Lyotard (1990), vinculado durante algún tiempo al grupo "Socialismo o Barbarie", exploró también la idea de la economía libidinal, sosteniendo que el 68 había sido la expresión de una nueva forma de deseo. Este deseo, expresado en las artes y en cualquier flujo de intercambio, estaba mediado por el discurso, a través de desplazamientos y derivas, formando parte de una economía libidinal que transitaba más por el lado del consumo que de la producción. El incremento sinfín del deseo se avenía bien con la reproducción ampliada del capital, pero era también un elemento importante para la construcción de una crítica política, como había ocurrido en el 68, donde se habían dado acciones singulares, directas, múltiples y efímeras, potenciando las intensidades libidinales y la creación.

Sin lugar a dudas, el 68 tuvo que ver con la explosión del individualismo, no desvinculado de lo colectivo. De acuerdo con Henri Weber, ese individualismo colectivo de izquierda, que reivindicaba, sí, la liberación del cuerpo y la ampliación de los objetos de deseo, pero en un sentido no consumista ni capitalista, sino guiado siempre por la conciencia crítica y la voluntad emancipadora, se tornó progresivamente en un individualismo conservador, ligado al mercado y a la maximización del beneficio en un sentido económico restringido.

Entre un individualismo libertario ligado a la expansión de la subjetividad y la reivindicación de la condición de ciudadanía o la constitución del espacio de la sociedad civil, no es nada extraño que surgiera una interpretación liberal, acomodada a los tiempos del neoliberalismo, incluso en la voz de uno de sus principales protagonistas, como lo fue Daniel Cohn Bendit (1978). El actual simpatizante del gobierno de Macron, que defiende las políticas del libre comercio, señala:

La conmemoración del 68 es una trampa, nuestro imaginario político está demasiado marcado por lo que sucedió hace cincuenta años, ahora vivimos en otro mundo, bajo otro sol. No creo que sea imposible revelarse, los movimientos radicales actuales no logran llegar a las masas, el 68 triunfó porque lo que lo hizo posible fue el hecho de no estar ideologizado, los pensadores de extrema izquierda llegaron después, cuando el tren ya estaba en marcha (El País, mayo 21 de 2018).

\section{El LEGADO UTÓPICO Y DEMOCRÁTICO DEL 68}

Las movilizaciones del 68 fueron una revolución cultural que inevitablemente tuvo un impacto político. Aun si en los procesos políticos inmediatos no se alteraron las 
estructuras de los estados ni la correlación de fuerzas entre las clases o los colectivos, fue a partir de las movilizaciones de mayo y la huelga general en Francia que terminó la era del gaullismo. En Praga, en Argentina y en México, los movimientos fueron aplastados por los tanques soviéticos y los soldados y paramilitares de los ejércitos argentino y mexicano, develando la naturaleza autoritaria de sus gobiernos, mientras que en Alemania las acciones violentas dieron lugar a la radicalización de algunos grupos. En general, los movimientos experimentaron formas de participación política diferentes a las que posibilita el Estado capitalista, tratando de superar las formas representativas de la política y poniendo en práctica modalidades autogestivas o autónomas, si queremos usar el lenguaje de Castoriadis. Aunque las movilizaciones tuvieron un carácter predominantemente cultural, las formas de vida por las que apostaban los jóvenes tenían un contenido inevitablemente anticapitalista que se orientó a la puesta en acción de una política de la vida.

Podemos ver esos movimientos como un acontecimiento, en el sentido de Alain Badiou (1998 y 2008), en la medida en que se hizo evidente la verdad universal de la incompatibilidad entre democracia y capitalismo, entre el incremento del consumo en su forma capitalista y la expansión de una subjetividad libre, soportada por un nuevo sujeto que incluía a los jóvenes estudiantes, la clase obrera y una multitud de ciudadanos-productores. Podemos evocarlos también como una amalgama de grupos que trascendieron a las series y advinieron también a una verdad universal mediante la praxis y la reciprocidad tanto horizontal como vertical, tal como lo veía Jean Paul Sartre en su Crítica de la razón dialéctica (1963).

La reciprocidad horizontal estaba en las asambleas, en la puesta en práctica de un nuevo cine (Bedenes Salazar, 2006) de un nuevo arte, en los grupos de discusión, en la marcha del silencio en México y las consignas de solidaridad con Vietnam, con la lucha del Che Guevara y las luchas de liberación de los pueblos africanos y asiáticos que se hicieron presentes en todos los movimientos. La reciprocidad vertical se presentaba en la recuperación de la revolución fallida de 1848 y la comuna de París en el Mayo Francés, en el reclamo de libertad para Valentín Campa y Demetrio Vallejo en México, así como en la voluntad de los estudiantes alemanes para desprenderse de su pasado nazi y ajustar cuentas con él, incluida la herencia heideggeriana. La huella del 68 mexicano estuvo presente también en los movimientos estudiantiles de 1986-88 y 1999-2000, y sin duda, en la rebelión cívico-electoral de 1988. Esa reciprocidad apuntaba al futuro en Praga, anticipando lo que sería la Revolución de Terciopelo en 
1989, con Vaclav Havel al frente, e inspirados en la obra de Karel Kosik, Karel Bartosek y Milan Kundera.

El 68 transformó el sistema y el mundo de la vida en una doble vertiente: por un lado, contribuyó a la ampliación e institucionalización de derechos, más allá de la democracia representativa, y modificó las pautas de vida; por otro, contribuyó a la reproducción ampliada del capitalismo, que en adelante tendría como eje central de acumulación la generación de conocimiento y la informatización de la sociedad, dando lugar a un capitalismo posmoderno que articulaba en un sistema mundial el posindustrialismo de las sociedades centrales, la industrialización de la periferia y la desposesión a las comunidades rurales de los recursos naturales. Estas transformaciones traerían como resultado la diversificación de los trabajadores asalariados, que en adelante entrecruzarían sus identidades como productores con las identidades étnicas y de género, reivindicando la condición de ciudadanía en un sentido ampliado y diferenciado.

Lo anterior incluye la construcción de colectividades reunidas en torno a estilos de vida, de consumo de música o drogas recreativas. Se generó así un espacio que también es objeto de una disputa política entre el mercantilismo hegemónico que tiende a subsumir y resignificar expresiones de una cultura popular, tornándola en hegemónica, a través de la globalización e intensificación de la industria cultural, luchando por la legitimidad de patrones normativos y estéticos. En estas disputas, lo que está en juego, más allá de la distribución económica, la ciudadanía y la identidad, es el espacio de la subjetividad. Será a partir de estas series complejas, producto de la expansión demográfica y del capitalismo, que se formen los nuevos grupos y sujetos en diferentes arenas y escalas espaciales, como hoy sucede con los nuevos movimientos donde interviene la generación millenial, con nuevas armas, nuevas herramientas, nuevos dispositivos y también nuevas demandas.

El movimiento global que se dio en 1968 tenía sin duda predominantemente rasgos anticapitalistas y democráticos, en la medida en que apuntaba a otras formas de participación, más allá de la forma-Estado, sin que dejara por ello de contribuir a una reforma democrática a mediano plazo dentro de las estructuras del capitalismo, y de que muchas de sus creaciones culturales fuesen subsumidas bajo la lógica de una industria cultural global (Lash y Lury, 2007). Podemos verlo como un movimiento biopolítico o como una forma de liberación, de autonomización del mundo de la vida de los poderes colonizadores del Estado y del mercado, que trataba de establecer una reciprocidad horizontal con las luchas de liberación nacional para entonces en curso, y 
una reciprocidad vertical con otros movimientos del pasado, proyectándose a su vez hacia las luchas del futuro, haciendo eco de la idea expresada por Benjamín (1940) en el sentido de que la historia es objeto de una construcción cuyo lugar no está constituido por el tiempo homogéneo y vacío, sino por un tiempo pleno, un tiempo-ahora.

\section{REFERENCIAS}

Aguayo, S. (2018). El 68. Los estudiantes, el presidente y la CIA. México: Ediciones Proceso.

Agustín, J. (2001). La contracultura en México. México: Debolsillo.

Álvarez Garín, R. (1998). La estela de Tlatelolco: una reconstrucción histórica del movimiento estudiantil del 68. México: Grijalbo.

Aron, R. (1983). El mayo francés. Nexos. Recuperado de https: / / www.nexos.com.mx/?p=4274).

Badiou, A. (1998). El ser y el acontecimiento. Buenos Aires: Manantial. . (2008). Lógicas de los mundos. Buenos Aires: Manantial.

Baynac, J., Ferry, L., Cohn Bendit, D., Finkielkraut, A. y Weber, H. (2018). Mai 68, Le débat. París: Gallimard.

Bedenes Salazar, P. (2006). La estética de las barricadas. Mayo del 68 y la creación artística. Barcelona: Universidad Jaume.

Benjamin, W. (2005 [1940)). Obras completas. Madrid: Abada.

Cohn Bendit, D. (1978). Nuestra comuna el 10 de mayo. En Cohn Bendit, D., Sartre, J.P., Y Marcuse, H., La imaginación al poder. París, mayo del 68. Barcelona: Argonauta, pp. 22-35.

Debord, G. (1995). La sociedad del espectáculo. Buenos Aires: Ediciones Naufragio.

Dosse, F. (1992). Historia del estructuralismo, Vol. II. Madrid: Akal.

Feixa, C. Fernández-Planells, A. y Figueras-Maz, M. (2016). Generación Hashtag. Los movimientos juveniles en la era de la web social. Revista Latinoamericana de Ciencias Sociales. Niñez y juventud (14) (1), pp. 107-120.

Ferry, L. y Renaut, A. (1985). El 68. La Pensée. París: Gallimard.

Guevara Niebla, G. (2008). 68. Largo camino a la democracia. México: Cal y Arena. Habermas, J. (1999). Problemas de legitimación en el capitalismo tardío. Madrid: Cátedra. . (2008). Teoría y praxis. Madrid: Tecnos.

Hall, S. (1970). Los hippies, una contracultura. Madrid: Anagrama. 
Heath J. y Potter A. (2005). Rebelarse vende: el negocio de la contracultura. México: Santillana Editores.

Hobsbawm, E. (1998). Historia del siglo XX. Barcelona: Crítica.

Kellner, M. (2018). La revuelta de los años sesenta en Alemania. Viento Sur. Recuperado de http: / / vientosur.info/spip.php?article13598.

LASH, S. Y LURY, C. (2007). Global cultural industry: The meadiating of things. Cambridge: Polity-Press.

Lyotard, J. F. (1990). Economía libidinal. México: Siglo XXI.

Marcuse, H. (1978). Declaraciones. En Cohn Bendit, D., Sartre, J.P. y Marcuse, H., La imaginación al poder. París, mayo del 68. Barcelona: Argonauta. pp. 51-63.

Marroquín, E. (1975). La contracultura como protesta. México: Joaquín Mortiz.

Meyer, J. (2009). El movimiento estudiantil en América Latina. Sociológica (68), pp. 179-195.

Morin, E, Lefort, C, y Castoriadis C. (2009). Mayo del 68: la brecha. Buenos Aires: Nueva Visión.

NTR. Periodismo crítico (Octubre 2, 2014). Recuerdo del movimiento estudiantil de 1968 divide a mexicanos. Recuperado de http://ntrzacatecas.com/2014/10/02/recuerdo-del-movimiento-estudiantildel-68-divide-a-mexicanos/

Paz, O. (1970). Posdata. México: Siglo XXI.

Revueltas, J. (1978). México 68, juventud y revolución. México: Era.

RoszaK, T. (1970). El nacimiento de una contracultura. Barcelona: Kairos.

Sartre, J. P. (1963). Crítica de la razón dialéctica. Vol. 2: Del grupo a la historia. Buenos Aires: Editorial Losada.

TARCUS, H. (2008). El mayo argentino. OSAL (X) (24), pp.161-180.

TARrow, S. (1994). El poder en movimiento. Movimientos sociales, acción colectiva y política. Madrid: Alianza Editorial.

Touraine, A. (1969). Le mouvement de mai ou le communisme utopique. París: Le Livre de Poche. . (1995). La producción de la sociedad. México: UNAM.

ViCEnTE, A. (mayo 22, 2018). Conmemorar Mayo del 68 es una trampa. El país. Recuperado de https://elpais.com/cultura/2018/05/21/actualidad/1526918790_160130.html

WALlerstein, I. (1990). 1968. Revolución en el sistema mundo, tesis e interrogantes. en Wallerstein I, Gunder Frank, A., Fuentes, M. y otros., El Juicio al sujeto. Un análisis global de los movimientos sociales (pp.15-45). México: FLACSO-PORRúA, 
ZermeÑo, S. (1978). México, una democracia utópica, México: Siglo XXI.

Zolov, E. (2009). La juventud se impone: Rebelión estudiantil y los temores de los mayores en México. 1968. De/Rotar, (1) (2), pp.102-108. 